Gut and Liver, Vol. 12, No. 6, November 2018, pp. 609-610

\title{
Efficacy of Direct-Acting Antivirals in Patients with Hepatitis C Virus/Human Immunodeficiency Virus Coinfection: A Gap between Clinical Trial and Real Practice
}

\author{
Do Young Kim
}

Department of Internal Medicine, Yonsei University College of Medicine, Seoul, Korea

See "Real-World Clinical Efficacy and Tolerability of Direct-Acting Antivirals in Hepatitis C Monoinfection Compared to Hepatitis C/ Human Immunodeficiency Virus Coinfection in a Community Care Setting" by Vijay Gayam, et al. on page 694, Vol. 12. No. 6, 2018

Hepatitis C virus (HCV) infection is a leading cause of death in individuals infected with human immunodeficiency virus (HIV), as HCV-related liver disease is accelerated by HIV. ${ }^{1}$ Therefore, effective treatment of both diseases is crucial to prevent liver related morbidity and mortality in this population. Fortunately, due to the potent antiretroviral therapy (ART), almost normal life expectancy can be expected if antiviral therapy is commenced before the onset of acquired immunodeficiency syndrome or advanced immunodeficiency. In terms of antiviral therapy for HCV infection, treatment with pegylated interferon and ribavirin had been challenging in HIV infected patients because of severe adverse events, drug-drug interaction as well as low cure rates, with sustained virologic response (SVR) rates ranging from $27 \%$ to $40 \%$. $^{2,3}$

Interferon-free all direct-acting antiviral (DAA) has opened a new era of HCV treatment even in patients with HCV/HIV coinfection. The SVR rates in several clinical trials, where various regimens including ledipasvir/sofosbuvir, daclatasvir plus sofosbuvir, sofosbuvir/velpatasvir, glecaprevir/pibrentasvir were used, ranged from 95\% to 98\%, which is similar to those in patients with HCV monoinfection. ${ }^{4-7}$ The question is that such high SVR rates in coinfected patients in clinical trial settings could be translated in the real-life practice. As is known well, there are strict inclusion and exclusion criteria for patient recruitment in clinical trials. Whereas, patients in real-life setting are quite heterogeneous, have concomitant diseases and medications. Specifically, patients coinfected with HCV/HIV in real clinical setting have a possibility of lower adherence to DAA and drugdrug interaction between DAA and ART medications. More im- portantly, in clinical trial, only patients with undetectable HIV RNA are enrolled, while in real practice the HIV status is variable.

Indeed, the reported SVR rates of coinfected patients in real practice is rather lower than in clinical trials. In a recent prospective Spanish cohort study, the SVR12 rates in subjects with HIV-coinfection treated with DAAs were 86.3\% (221/256 patients), which were significantly lower than 94.9\% (205/216) in subjects with HCV monoinfection treated with DAAs $(\mathrm{p}=0.002){ }^{8}$ In addition, HIV infection was found to be an independent predictor of non-achievement of SVR12 in the multivariate logistic regression analysis. However, it should be noted that around one half $(42 \%, 108 / 256)$ of the HCV/HIV coinfected patients received simeprevir + sofosbuvir, which has been associated with treatment failure.

In the article by Gayam et al., ${ }^{9}$ the efficacy and tolerability of DAAs were retrospectively studied in patients $(n=74)$ with HCV/ HIV coinfection compared to those $(n=253)$ with HCV monoinfection. ${ }^{9}$ The black was the most frequent race, accounting for $64.5 \%$ of the entire population. There were 68 (20.8\%) prior treatment-experienced patients, and the most common genotype was $1 \mathrm{a}$ in the both groups (62.2\% in coinfection vs $53.4 \%$ in monoinfection). The proportion of patients with compensated cirrhosis was comparable (14\% vs 23\%, $p=0.103$ ). Unlike in clinical trials, some coinfected patients had detectable HIV RNA in blood. The overall SVR rates in all the patients were 94\%. The SVR was higher in HCV monoinfected patients compared to those with HCV/HIV coinfection (96\% vs 86\%, p=0.005). In multivariate regression analysis, positive HIV was the only in-

\footnotetext{
Correspondence to: Do Young Kim

Department of Internal Medicine, Yonsei University College of Medicine, 50-1 Yonsei-ro, Seodaemun-gu, Seoul 03722, Korea

Tel: +82-2-2228-1992, Fax: +82-2-393-6884, E-mail: dyk1025@yuhs.ac pISSN 1976-2283 eISSN 2005-1212 https://doi.org/10.5009/gnl18418
}

@ This is an Open Access article distributed under the terms of the Creative Commons Attribution Non-Commercial License (http://creativecommons.org/licenses/by-nc/4.0) which permits unrestricted non-commercial use, distribution, and reproduction in any medium, provided the original work is properly cited. 
dependent factor to predict achieving SVR, while HIV viral load and CD4 cell count were not identified to be predictor of treatment response.

Are SVR rates in HCV/HIV coinfected patients really lower than in mono-infected patients in real clinical practice? Another prospective cohort study from Spain shows a similar SVR rates between coinfected and monoinfected patients. ${ }^{10}$ Among a total of 1,634 patients, there were 1,152 (70\%) HCV-monoinfected patients and 482 (30\%) HCV/HIV-coinfected patients. The SVR12 rates were 97\% and 94\% in monoinfected and coinfected patients, respectively. There was also no difference in SVR12 rates between two groups even after adjustment for cirrhosis, genotype, and DAA combination.

What would make a difference in SVR rates between coinfected and monoinfected patients, or between clinical trial and real practice setting? Patients infected with HIV have several characteristics. Due to the ART for HIV, drug-drug interactions must be considered carefully in each HIV-coinifected patient prior to commencing DAA therapy, which can be quite challenging to the prescribing physicians. Another factor to be consider is that HIV-infected patients might be less compliant to the HCV medications. Thus, a close cooperation between hepatologist and HIV specialist is essential to have a success in the treatment of HCV/ HIV coinfected patients. In the article of Gayam et al., ${ }^{9}$ the DAA regimen seems to be selected with an assistance by HIV specialist in order to have less drug interaction and fewer side effects. However, it is uncertain whether the most appropriate regimen was actually chosen for each coinfected patient. Furthermore, it is also questionable whether coinfected patients had acceptable compliance to the DAAs. Apart from these factors, several other socio-economic and clinical variables might affect the treatment outcomes in HCV/HIV coinfected patients. Lastly, it is a hypothesis that the cause of lower SVR rates to DAA therapy, as well as higher relapse rates, in HCV/HIV coinfected patients are due to the effect of HIV on the immune system and its response to HCV infection. ${ }^{8}$

The authors in the article also investigated the tolerability of DAAs in coinfected patients compared with monoinfected patients. Overall, the incidence of various adverse events including fatigue, anemia and leukopenia was similar in the two groups, confirming the results of previous study. ${ }^{9}$

$\mathrm{HCV} / \mathrm{HIV}$ coinfected patients are included in "special population" because the selection of DAA regimen should be made after consideration of patient's HIV status, presence of cirrhosis, prior treatment experience, and concomitant HIV medication. However, with potent and safe DAAs, coinfected patients would be no longer special population in near future.

It is yet unsolved issue whether the response to DAAs in HCV/ HIV coinfected patients is worse than in HCV monoinfected patients. In clinicals trial with strict pre-defined design, there is no difference of SVR rates between coinfected and monoinfected patients. However, several real-life data including Gayam's study have indicated lower SVR rates in coinfected patients. Based on the factors which might affect treatment outcomes in this population, physicians need to bear in mind that patients should be kept on proper DAA regimen, good drug compliance, and co-treatment of HIV infection.

\section{CONFLICTS OF INTEREST}

No potential conflict of interest relevant to this article was reported.

\section{REFERENCES}

1. Limketkai BN, Mehta SH, Sutcliffe CG, et al. Relationship of liver disease stage and antiviral therapy with liver-related events and death in adults coinfected with HIV/HCV. JAMA 2012;308:370378

2. Chung RT, Andersen J, Volberding P, et al. Peginterferon alfa2a plus ribavirin versus interferon alfa-2a plus ribavirin for chronic hepatitis C in HIV-coinfected persons. N Engl J Med 2004;351:451-459.

3. Carrat F, Bani-Sadr F, Pol S, et al. Pegylated interferon alfa-2b vs standard interferon alfa-2b, plus ribavirin, for chronic hepatitis $\mathrm{C}$ in HIV-infected patients: a randomized controlled trial. JAMA 2004;292:2839-2848.

4. Naggie S, Cooper C, Saag M, et al. Ledipasvir and sofosbuvir for HCV in patients coinfected with HIV-1. N Engl J Med 2015;373:705-713.

5. Wyles DL, Ruane PJ, Sulkowski MS, et al. Daclatasvir plus sofosbuvir for HCV in patients coinfected with HIV-1. N Engl J Med 2015;373:714-725.

6. Wyles D, Bräu N, Kottilil S, et al. Sofosbuvir and velpatasvir for the treatment of hepatitis $\mathrm{C}$ virus in patients coinfected with human immunodeficiency virus type 1: an open-label, phase 3 study. Clin Infect Dis 2017;65:6-12.

7. Rockstroh JK, Lacombe K, Viani RM, et al. Efficacy and safety of glecaprevir/pibrentasvir in patients coinfected with hepatitis $\mathrm{C}$ virus and human immunodeficiency virus type 1: the EXPEDITION-2 study. Clin Infect Dis 2018;67:1010-1017.

8. Neukam K, Morano-Amado LE, Rivero-Juárez A, et al. HIVcoinfected patients respond worse to direct-acting antiviralbased therapy against chronic hepatitis $\mathrm{C}$ in real life than HCVmonoinfected individuals: a prospective cohort study. HIV Clin Trials 2017;18:126-134.

9. Gayam V, Hossain MR, Khalid M, et al. Real-world clinical efficacy and tolerability of direct-acting antivirals in hepatitis $C$ monoinfection compared to hepatitis $\mathrm{C} /$ human immunodeficiency virus coinfection in a community care setting. Gut Liver 2018;12:694-703.

10. Montes ML, Olveira A, Ahumada A, et al. Similar effectiveness of direct-acting antiviral against hepatitis $\mathrm{C}$ virus in patients with and without HIV infection. AIDS 2017;31:1253-1260. 